\title{
MORTALITY RATE OF HUNTINGTON DISEASE IN JAPAN : SECULAR TRENDS, MARITAL STATUS, AND GEOGRAPHICAL VARIATIONS
}

\author{
Yoko IMAIzUMI \\ Institute of Population Problems, Ministry of Health and Welfare, \\ Chiyoda-ku, Tokyo 100, Japan
}

\begin{abstract}
Summary The death rate from Huntington disease (HD) in Japan was analyzed using Japanese vital statistics for 1969-1985. There was no significant change in the HD death rate over the years. The overall death rate per million population was 0.15 for both sexes. As for marital status, a quarter of the HD deaths was the single group for both sexes. There were remarkable differences in the HD death rates for each sex among the four marital categories. The geographical variations in the HD death rate were observed with the highest death rate in Tokushima prefecture (1.03). The excess of observed than expected numbers of HD deaths was obtained in the occupational category VI (other) of the head of household. The mean age at death in HD was nearly constant during the period, and overall mean age at death was 48 years for both sexes, which value was eight years shorter than that in South Wales.
\end{abstract}

Key Words Huntington disease, mortality rate, marital status, geographical variation

\section{INTRODUCTION}

The Huntington disease (HD) is an autosomal dominant character. Recently, the HD gene was assigned to chromosome 4 (Gusella et al., 1983). In most Western countries the prevalence rates of $\mathrm{HD}$ were between 30 and 70 per million population (McKusick, 1988). On the other hand, the lowest prevalence rate has been found in South African blacks (0.6: Hayden, 1977), Japan (1.1-3.8: Kanazawa, 1983; Kishimoto et al., 1957), and Finland (5: Palo et al., 1987). In Japan, the prevalence rates of HD was three times higher in Aichi (Kishimoto et al., 1957) than in Ibaraki prefecture (Kanazawa, 1983). Therefore it is of interest to know geographical variations in the HD death rate in Japan.

The present study deals with the secular changes in the HD death rate during

Received April 17, 1989; revised version received May 12, 1989; Accepted May 23, 1989 
the period from 1969 to 1985 and the geographical variations in the HD death rate during the period from 1979 to 1985 in Japan. It also deals with the effects of marital status and occupation of the head of the household on the HD death rate during the period from 1979 to 1985.

\section{MATERIALS AND METHODS}

Data consisting of 263 HD deaths reported for 1969-1985 inclusive have been obtained from the death certificate records kept at the Ministry of Health and Welfare, Japan. The International Classification of Diseases in 1968 assigned a code 331.0 for HD in the eight edition and a code 333.4 in the ninth edition in 1979 . The certificate includes information on occupation of the head of the household, marital status, sex, place of residence, dates of birth and death, and cause of death.

In computing the HD death rate, the number of deaths from HD in each sex were divided by the population size of each sex during the same period. On the other hand, in computing the regional HD death rate, the average population of the two census years, 1980 and 1985, was used as the denominator in each prefecture.

Table 1. Death rate of Funtington disease by sex during 1969-1985.

\begin{tabular}{|c|c|c|c|c|c|c|}
\hline \multirow{2}{*}{ Year } & \multicolumn{3}{|c|}{ Number of deaths } & \multicolumn{3}{|c|}{ Death rate per million population } \\
\hline & Males & Females & Total & Males & Females & Total \\
\hline 1969 & 3 & 7 & 10 & 0.060 & 0.135 & 0.098 \\
\hline 1970 & 3 & 7 & 10 & 0.059 & 0.133 & 0.097 \\
\hline 1971 & 10 & 6 & 16 & 0.195 & 0.113 & 0.153 \\
\hline 1972 & 5 & 8 & 13 & 0.096 & 0.148 & 0.123 \\
\hline 1973 & 4 & 13 & 17 & 0.075 & 0.236 & 0.157 \\
\hline 1974 & 8 & 7 & 15 & 0.149 & 0.126 & 0.137 \\
\hline 1975 & 9 & 9 & 18 & 0.164 & 0.159 & 0.162 \\
\hline 1976 & 7 & 3 & 10 & 0.127 & 0.053 & 0.089 \\
\hline 1977 & 11 & 6 & 17 & 0.197 & 0.104 & 0.150 \\
\hline 1978 & 7 & 4 & 11 & 0.124 & 0.069 & 0.096 \\
\hline 1979 & 9 & 9 & 18 & 0.158 & 0.154 & 0.156 \\
\hline 1980 & 7 & 5 & 12 & 0.122 & 0.085 & 0.103 \\
\hline 1981 & 10 & 6 & 16 & 0.173 & 0.101 & 0.137 \\
\hline 1982 & 5 & 10 & 15 & 0.086 & 0.167 & 0.127 \\
\hline 1983 & 13 & 14 & 27 & 0.222 & 0.232 & 0.227 \\
\hline 1984 & 5 & 7 & 12 & 0.085 & 0.115 & 0.100 \\
\hline 1985 & 12 & 14 & 26 & 0.203 & 0.229 & 0.216 \\
\hline
\end{tabular}




\section{RESULTS}

Secular change in the HD mortality rate

Table 1 shows secular changes in the HD death rates for each sex during the period from 1969 to 1985 . The death rate was slightly increased with the year. The linear regression coefficients of the HD death rate on the year (per 100,000 years) were $0.00043( \pm 0.00025)$ for males, $0.00019( \pm 0.00027)$ for females, and 0.00031 $( \pm 0.00019)$ for total. These values were not significant at the $5 \%$ level. The overall HD death rate was 0.15 per million for both sexes.

\section{Age-group specific mortality rate of $H D$}

Table 2 shows the age-group specific HD death rates by sex during the period from 1969 to 1985 . In both sexes, the HD death rate was gradually increased up to the 30-34 age group and suddenly increased thereafter up to the 55-59 age group for males and the 50-54 age group for females, and decreased thereafter.

\section{Marital status}

Table 3 shows the age-group specific HD death rates by sex and marital status during the period from 1979 to 1985 . To compute the age-group specific HD death rate by sex and marital status during the period, the average population at 15 years and over for the two census years, 1980 and 1985, was used as the denominator. The HD death rate in each age category was higher in the single than in the married group for both sexes, except over 65 years of age for males and over 55 years of age for females.

Table 4 illustrates average annual age-adjusted HD death rates by sex and matiral status which were computed using age-group specific HD death rates in each marital status for 1979-1985 (Table 3) and the size of the population at 15 years and over. The lowest age-adjusted death rate per million was seen in the widowed group for males (0) and in the married group for female (0.12). On the other hand, the highest death rate for males was seen in the divorced (1.03), followed in order by the single $(0.63)$ and the married group (0.13), whereas the highest death rate for females was seen in the single $(0.47)$ followed in order by the divorced $(0.45)$ and the widowed group $(0.43)$.

\section{Geographical variation}

Table 5 shows the HD death rate by prefecture during the period from 1979 to 1985 . The overall HD death rate was 0.15 per million. The highest death rate was seen in Tokushima prefecture (1.03), followed by Yamagata (0.80), and Wakayama (0.53) prefectures. Therefore, the HD death rate in Tokushima prefecture was seven times as high as the overall HD death rate in Japan. On the other hand, the lowest death rate (0) was seen in 13 prefectures (see Table 5). Second lowest HD death rate was seen in Saitama prefecture (0.05). 
Table 2. Deaths and average annual death rates for Huntington disease (HD) by age and sex, 1969-1985.

\begin{tabular}{|c|c|c|c|}
\hline Age & Male & Female & Total \\
\hline & \multicolumn{3}{|c|}{ Number of deaths with Huntington disease } \\
\hline Total & 128 & 135 & 263 \\
\hline Under 4 & 0 & 0 & 0 \\
\hline $5-9$ & 1 & 1 & 2 \\
\hline $10-14$ & 2 & 2 & 4 \\
\hline $15-19$ & 0 & 3 & 3 \\
\hline $20-24$ & 4 & 2 & 6 \\
\hline $25-29$ & 8 & 6 & 14 \\
\hline $30-34$ & 6 & 8 & 14 \\
\hline $35-39$ & 12 & 11 & 23 \\
\hline $40-44$ & 16 & 23 & 39 \\
\hline $45-49$ & 20 & 18 & 38 \\
\hline $50-54$ & 16 & 20 & 36 \\
\hline $55-59$ & 16 & 14 & 30 \\
\hline $60-64$ & 11 & 10 & 21 \\
\hline $65-69$ & 9 & 8 & 17 \\
\hline $70-74$ & 5 & 4 & 9 \\
\hline \multirow[t]{2}{*}{ Over 75} & 2 & 5 & 7 \\
\hline & \multicolumn{3}{|c|}{ Average annual death rate of $H D$ per million population } \\
\hline Total & 0.136 & 0.139 & 0.138 \\
\hline Under 4 & 0 & 0 & 0 \\
\hline $5-9$ & 0.013 & 0.013 & 0.013 \\
\hline $10-14$ & 0.027 & 0.028 & 0.027 \\
\hline $15-19$ & 0 & 0.043 & 0.021 \\
\hline $20-24$ & 0.052 & 0.027 & 0.040 \\
\hline $25-29$ & 0.102 & 0.077 & 0.089 \\
\hline $30-34$ & 0.075 & 0.100 & 0.087 \\
\hline $35-39$ & 0.159 & 0.146 & 0.153 \\
\hline $40-44$ & 0.229 & 0.329 & 0.279 \\
\hline $45-49$ & 0.325 & 0.281 & 0.303 \\
\hline $50-54$ & 0.314 & 0.354 & 0.335 \\
\hline $55-59$ & 0.391 & 0.289 & 0.335 \\
\hline $60-64$ & 0.333 & 0.244 & 0.284 \\
\hline $65-69$ & 0.330 & 0.237 & 0.279 \\
\hline $70-74$ & 0.243 & 0.152 & 0.192 \\
\hline Over 75 & 0.093 & 0.150 & 0.128 \\
\hline
\end{tabular}


Table 3. Deaths and average annual death rates for Huntington disease (HD) by age, sex and marital status, 1979-1985.

\begin{tabular}{|c|c|c|c|c|c|c|c|c|}
\hline \multirow{2}{*}{ Age } & \multicolumn{4}{|c|}{ Male } & \multicolumn{4}{|c|}{ Female } \\
\hline & Single & Married & Widowed & Divorced & Single & Married & Widowed & Divorced \\
\hline & \multicolumn{8}{|c|}{ Number of deaths with Huntington disease } \\
\hline Total & 16 & 38 & 0 & 7 & 16 & 30 & 12 & 6 \\
\hline Under 15 & 2 & - & 一 & - & 1 & - & - & - \\
\hline $15-24$ & 2 & 0 & 0 & 0 & 4 & 0 & 0 & 0 \\
\hline $25-34$ & 3 & 0 & 0 & 0 & 5 & 0 & 0 & 0 \\
\hline $35-44$ & 6 & 5 & 0 & 6 & 3 & 9 & 2 & 1 \\
\hline $45-54$ & 2 & 13 & 0 & 1 & 3 & 11 & 0 & 2 \\
\hline $55-64$ & 1 & 14 & 0 & 0 & 0 & 8 & 2 & 3 \\
\hline \multirow[t]{2}{*}{ Over 65} & 0 & 6 & 0 & 0 & 0 & 2 & 8 & 0 \\
\hline & \multicolumn{8}{|c|}{ Average annual death rate of HD per million population } \\
\hline Total & $0.176^{\mathrm{a}}$ & 0.181 & 0 & 1.561 & $0.226^{\mathrm{a}}$ & 0.143 & 0.288 & 0.660 \\
\hline Under 15 & 0.000 & - & - & - & 0.000 & - & - & - \\
\hline $15-24$ & 0.035 & 0 & 0 & 0 & 0.078 & 0 & 0 & 0 \\
\hline $25-34$ & 0.117 & 0 & 0 & 0 & 0.444 & 0 & 0 & 0 \\
\hline $35-44$ & 1.013 & 0.086 & 0 & 4. 264 & 0.842 & 0.154 & 1.827 & 0.403 \\
\hline $45-54$ & 1.116 & 0.256 & 0 & 0.772 & 1.235 & 0.233 & 0 & 0.873 \\
\hline $55-64$ & 1.672 & 0.420 & 0 & 0 & 0 & 0.260 & 0.231 & 1.717 \\
\hline Over 65 & 0 & 0.220 & 0 & 0 & 0 & 0.117 & 0.284 & 0 \\
\hline
\end{tabular}

a Including number of deaths with HD under 15 years old.

Table 4. Average annual age-adjusted death rates for Huntington disease, by age, sex, and marital status, 1979-1985.

\begin{tabular}{lccc}
\hline \multirow{2}{*}{ Marital status } & \multicolumn{3}{c}{ Age-adjusted death rate per million population more than 14 years of age } \\
\cline { 2 - 4 } & Male & Female & Male/Female \\
\hline Single & 0.628 & 0.471 & 1.33 \\
Married & 0.134 & 0.120 & 1.12 \\
Widowed & 0 & 0.431 & 0 \\
Divorced & 1.025 & 0.447 & 2.29 \\
\hline
\end{tabular}

It is called a city or town and village according to whether the population size of the administrative unit is over 30,000 or not. The census districts were divided into two groups: urban (city) and rural (town and village) areas. The HD death rate during the period from 1979 to 1985 was slightly higher in the former areas 
Table 5. Death rate of Huntington disease per million population in each prefecture, 1979-1985.

\begin{tabular}{|c|c|c|c|c|c|}
\hline Prefecture & Number of deaths & Death rate & Prefecture & Number of deaths & Death rate \\
\hline Whole of Japan & 126 & 0.151 & & & \\
\hline Hokkaido & 5 & 0.127 & Shiga & 1 & 0.128 \\
\hline Aomori & 0 & 0.000 & Kyoto & 4 & 0.223 \\
\hline Iwate & 1 & 0.100 & Osaka & 9 & 0.150 \\
\hline Miyagi & 3 & 0.201 & Hyogo & 3 & 0.082 \\
\hline Akita & 3 & 0.341 & Nara & 1 & 0.114 \\
\hline Yamagata & 7 & 0.796 & Wakayama & 4 & 0.526 \\
\hline Fukushima & 2 & 0.139 & Tottori & 0 & 0.000 \\
\hline Ibaraki & 0 & 0.000 & Shimane & 1 & 0.181 \\
\hline Tochigi & 2 & 0.156 & Okayama & 1 & 0.075 \\
\hline Gunma & 0 & 0.000 & Hiroshima & 4 & 0.206 \\
\hline Saitama & 2 & 0.051 & Yamaguchi & 0 & 0.000 \\
\hline Chiba & 6 & 0.173 & Tokushima & 6 & 1.033 \\
\hline Tokyo & 12 & 0.146 & Kagawa & 0 & 0.000 \\
\hline Kanagawa & 6 & 0.119 & Ehime & 3 & 0.282 \\
\hline Niigata & 1 & 0.058 & Kochi & 0 & 0.000 \\
\hline Toyama & 1 & 0.129 & Fukuoka & 8 & 0.247 \\
\hline Ishikawa & 1 & 0.126 & Saga & 2 & 0.327 \\
\hline Fukui & 0 & 0.000 & Nagasaki & 0 & 0.000 \\
\hline Yamanashi & 1 & 0.175 & Kumamoto & 0 & 0.000 \\
\hline Nagano & 3 & 0.203 & Oita & 2 & 0.231 \\
\hline Gifu & 4 & 0.287 & Miyazaki & 0 & 0.000 \\
\hline Shizuoka & 3 & 0.122 & Kagoshima & 0 & 0.000 \\
\hline Aichi & 9 & 0.203 & Okinawa & 0 & 0.000 \\
\hline Mie & 4 & 0.333 & Unknown & 1 & - \\
\hline
\end{tabular}

(0.16 per million) than the latter (0.12), where the number of HD deaths were 102 and 24 , respectively.

\section{Occupation}

Table 6 shows the number of HD deaths by occupation of the head of the household. These occupations were classified into six categories according to the classification in the certificate records: I (agriculture only), II (agriculture with other work), III (self employed), IV (white collar), V (blue collar) and VI (other). Expected numbers of deaths in Table 5 were calculated based on the total numbers of HD deaths for 1979-1985 and the rate of each occupation of the head of the household in total number of deaths for 1979-1985. The number of HD deaths was 
Table 6. Observed and expected numbers of deaths from Huntington disease (HD) by occupation of the head of the household, 1979-1985.

\begin{tabular}{|c|c|c|c|c|}
\hline \multicolumn{2}{|r|}{ Occupation } & \multicolumn{2}{|c|}{ Number of HD } & \multirow[t]{2}{*}{$\chi^{2}$} \\
\hline \multirow[t]{2}{*}{ I } & Agriculture only & Obs. & 8 & \\
\hline & & Exp. & 13 & 1.92 \\
\hline \multirow[t]{2}{*}{ II } & Agriculture with other works & Obs. & 10 & \\
\hline & & Exp. & 17 & 2.88 \\
\hline \multirow[t]{2}{*}{ III } & Self employed & Obs. & 12 & \\
\hline & & Exp. & 17 & 1.47 \\
\hline \multirow[t]{2}{*}{ IV } & Employee (white collar) & Obs. & 11 & \\
\hline & & Exp. & 18 & 2.72 \\
\hline \multirow[t]{2}{*}{$\mathrm{V}$} & Employee (blue collar) & Obs. & 25 & \\
\hline & & Exp. & 19 & 1.89 \\
\hline & Other & Obs. & 60 & \\
\hline & & Exp. & 42 & 7. $71^{*}$ \\
\hline
\end{tabular}

* Significant at the $1 \%$ level.

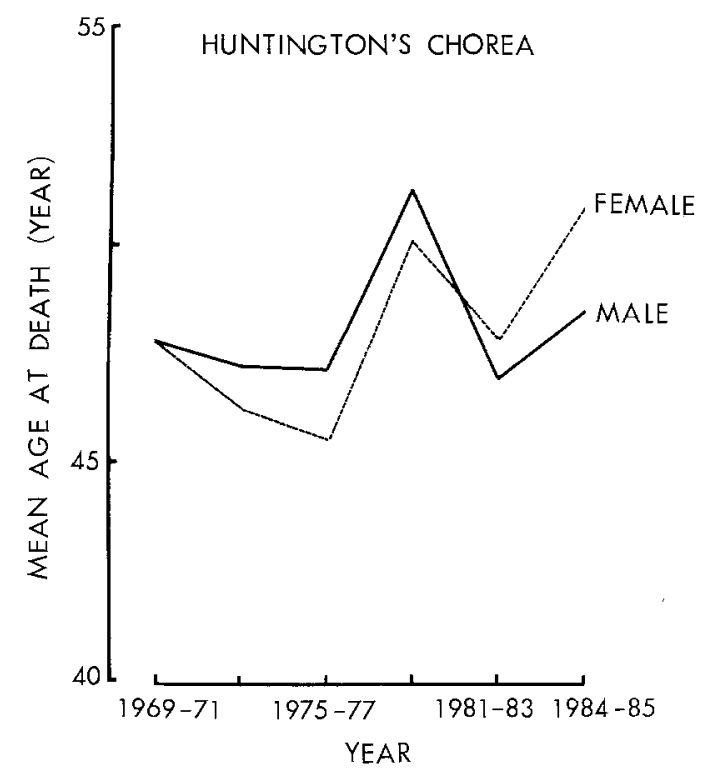

Fig. 1. Trends of mean age at death of Huntington disease by sex, during 1969-1985.

higher in the observed than in the expected values for categories V and VI, whereas the opposite tendency was seen in categories I through IV. The difference between the observed and the expected numbers of $\mathrm{HD}$ deaths was statistically significant in category VI.

\section{Mean age at death}

Figure 1 shows the secular changes in the mean age at death from HD in each 


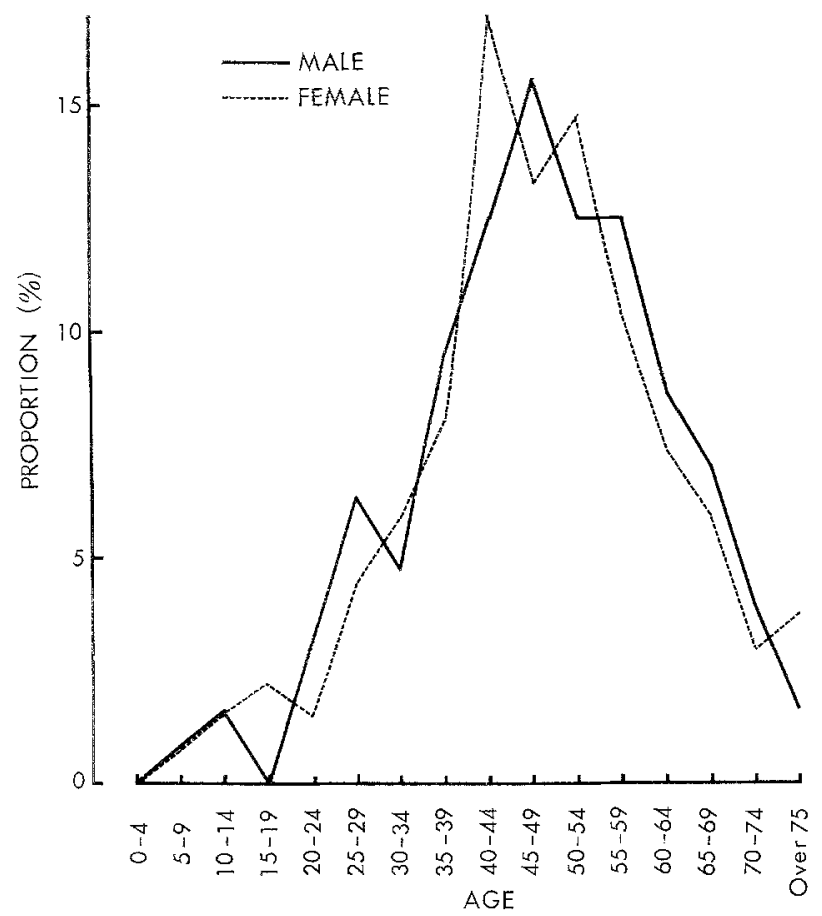

Fig. 2. Distribution of age at death in Huntington disease by sex, during 1969-1985.

sex during the period from 1969 to 1985 . The mean age at death in HD was 47.8 years for both sexes in 1969-1971 and the corresponding age in 1984-1985 was 48.5 years for males and 50.9 years for females. Then mean age at death in HD was nearly constant during the period for both sexes, and overall mean age \pm S.D. at death was $48.1 \pm 1.6$ years for males and $48.2 \pm 2.1$ years for females.

Figure 2 shows the distribution of age at death in HD, which values were obtained from Table 2. Age at death in HD ranged from 5-9 years to over 75 years. Among the 263 cases six percentage of HD patients died under 25 years old and $54.4 \%$ under 50 years.

\section{DISCUSSION}

According to Kurtzke (1979), it was possible to obtain all deaths listed as HD anywhere on the certificates in Sweden (1969 to 1974) and Denmark (1961-1975). In these countries, the HD death rates were separately obtained for "underlying cause of death," which constitutes of $68 \%$ of all deaths listed as HD, and remaining $32 \%$ for "contributory cause of death" or an "associated condition." However, these values are not obtained in Japan. Routinely reported death data on the certificate record are based solely on deaths coded as underlying (primary) cause. 
Therefore the HD death rate $(0.15$ per million) in the present study was underestimate.

The HD death rate in Japan was approximately one-tenth the values from the Western Hemisphere (Kurtzke, 1979) and United States whites (Kurtzke et al., 1977). Similar tendency was also observed in the prevalence rates of HD (McKusick, 1988; Kishimoto et al., 1957). As to geographical variation, the prevalence rate in HD was three times higher in Aichi (Kishimoto et al., 1957) than in Ibaraki prefecture (Kanazawa, 1983), whereas the corresponding HD death rates per million in the present study were 0.20 and 0 , respectively. It is suggested that the geographical variations in the HD death rate may represent these in the prevalence rate in Japan. Hogg et al. (1979) computed regional HD death rates for the entire United States during the period from 1968 to 1974, where regional variation in rates of death due to HD was not marked. In the present study the $\mathrm{HD}$ death rate varied from zero in 13 prefectures to 1.03 per million in Tokushima prefecture (Table 5). Hogg et al. (1979) mentioned that regional mortality rates may reflect morbidity patterns and be useful in planning health care facilities and research centers.

According to Kurtzke et al. (1977), the age-group specific HD death rate was highest at 60 to 70 years in all studied populations, except among the Japanese, with earlier peak at 50 years. In the present study the age-group specific HD death rate was highest at 55 to 59 years for males and at 50 to 54 years for females.

According to Kishimoto et al. (1957), the estimate of relative fitness in HD was 0.65 in Japan. Fitness has two main components: viability and fertility. The latter component consists of the rates of marriage and of leaving offspring. In the present study, the proportion of the single group in HD deaths for the size of the population at 15 years and over was $24 \%$ for both sexes during the period from 1979 to 1985 (Table 3 ), whereas the values in all deaths were $7 \%(177,146 / 2,675,672)$ for males and $5 \%(120,210 / 2,275,347)$ for females. Then the rate of marriage was $76 \%$ among HD deaths and $94 \%$ among all deaths. Accordingly the rate of marriage was reduced $19 \%(1-0.76 / 0.94)$ in HD patients.

According to Walker et al. (1981), the mean age \pm S.D. at onset and at death in $\mathrm{HD}$ was $41.2 \pm 12.7$ and $56.5 \pm 12.2$ years in South Wales, respectively. In the present study, overall mean age at death in HD was 48 years for both sexes. Therefore the Japanese HD patients may have a short life span compared with those in South Wales. Mean age at death in HD can be used as a parameter of genetic counselling.

Acknowledgments I am indebted to Dr. Eiji Inouye for helpful comments of earlier draft of this paper.

\section{REFERENCES}

Gusella, J.F., Wexler, N.S., Conneally, P.M., Naylor, S.L., Anderson, M.A., Tanzi, R.E., Watkins, P.C., Ottina, K., Wallace, M.R., Sakaguchi, A.Y., Young, A.B., Schoulson, I., Bonilla, E. 
and Martin, J.B. 1983. A polymorphic DNA marker genetically linked to Huntington's disease. Nature 306: 234-238.

Hayden, M.R. and Beighton, P. 1977. Huntington's chorea in the Cape coloured comnunity of South Africa. South Afr. Med. J. 52: 886-888.

Hogg, J.E., Massey, E.W. and Schoenberg, B.S. 1979. Mortality from Huntington's disease in the United States. Adv. Neurol. 23: 27-35.

Japan, Ministry of Health and Welfare: Vital Statistics, 1969-1985 (in Japanese), Health and Welfare Statistics and Information Department, Ministry of Health and Welfare, Tokyo, 1971 1987.

Kanazawa, I. 1983. On prevalence rate of Huntington's disease in Ibaraki Prefecture. In $A n$ nual Report of the Research Committee of CNS Degenerative Diseases (Summary in English), The Ministry of Health and Welfare of Japan, pp. 151-156.

Kishimoto, K., Nakamura, M. and Sotokawa, Y. 1957. Population genetics of Huntington's chorea in Japan. In Annual Report of the Research Institute of Environmental Medicine (in Japanese), Nagoya University, Nagoya, Vol. 9, pp. 195-211.

Kurtzke, J.F. 1979. Huntington's disease: mortality and morbidity data from outside the United States. Adv. Neurol. 23: 13-25.

Kurtzke, J.F., Anderson, V.E., Beebe, G.W., Elston, R.C., Higgins, I., Hogg, J., Kurland, L., Muenter, M., Myrianthopoulos, N., Reed, T.E., Schoenberg, B., Schull, W.J. and Li, C.C. 1977. Report of the Work Group on Epidemiology, Biostatistics, and Population Genetics. In Report: Commission for the Control of Huntington's Disease and Its Consequences. Vol. III, Part 1-Work Group Reports, Research. DHEW Pub. No. (NIH) 78-1503, pp. 1-133 to 1236, US Government Printing Office, Washington, D.C.

McKusick, V.A. 1988. Mendelian Inheritance in Man: Catalogs of Autosomal Dominant, Autosomal Recessive, and X-linked Phenotypes (8th Ed.), Johns Hopkins Univ. Press, Baltimore.

Palo, J., Somer, H., Ikonen, E., Karila, L. and Peltonen, L. 1987. Low prevalence of Huntington's disease in Finland. Lancet I: 805-806.

Walker, D.A., Harper, P.S., Wells, C.E.C., Tyler, A., Davies, K. and Newcombe, R.G. 1981. Huntington's chorea in South Wales. A genetic and epidemiological study. Clin. Genet. 19: 213-221. 